\title{
Observations in the polar middle atmosphere by rocket-borne Rayleigh lidar: First results
}

\author{
Ulf-Peter Hoppe ${ }^{1}$, Torkild Eriksen ${ }^{1}$, Eivind V. Thrane ${ }^{1}$, Tom A. Blix ${ }^{1}$, Jens Fiedler ${ }^{2}$, and Franz-Josef Lübken ${ }^{3}$ \\ ${ }^{1}$ Norwegian Defence Research Establishment, Norway \\ ${ }^{2}$ Leibniz-Institute of Atmospheric Physics, Germany \\ ${ }^{3}$ Physikalisches Institut der Universität Bonn, Germany
}

(Received August 17, 1998; Revised May 24, 1999; Accepted May 24, 1999)

\begin{abstract}
We present a new rocket instrument which measures total atmospheric density with great precision and resolution by Rayleigh scattering of infrared light. Comparison with a ground-based lidar shows: (a) both instruments measure the same physical parameters, even though they have different integration times and volumes. (b) The observed density structures change little over the course of an hour and the horizontal distance of $14 \mathrm{~km}$. The rocket instrument has a basic vertical resolution of approximately $8 \mathrm{~m}$ and a number density precision of $4.2 \cdot 10^{19} \mathrm{~m}^{-3}$. Above 56 $\mathrm{km}$ we integrate over an increasing vertical range, reaching $80 \mathrm{~m}$ at $70 \mathrm{~km}$. The measured number density profile shows remarkable alternations between very stable layering and metastable layering (adiabatic lapse rate) in the atmosphere between $52 \mathrm{~km}$ and $71 \mathrm{~km}$. Comparison with the hodograph of the horizontal wind profile measured by a falling sphere 29 minutes later shows that the metastable height regions coincide with height regions where the hodograph deviates from an ideal spiral. The observation is tentatively interpreted as a gravity wave that is saturating (or encountering a critical level) in these height regions. The comparison of the fine-scale neutral number density observations with measurements of ion density by electrostatic skin probes on board the same vehicle shows a number of ion density enhancements in the stably-layered height regions. With one exception out of six cases, these enhancements occur where the vertical gradient of the meridional wind would collect positive ions as in sporadic $\mathrm{E}$ layers. This may be the first observation of such ion density enhancements in the height region 55 to $70 \mathrm{~km}$.
\end{abstract}

\section{Introduction}

The density structure of the mesosphere is routinely measured by ground-based lidars with height resolutions of typically $100 \mathrm{~m}$ and a time resolution of one to several hours (e.g., Fiedler et al., 1997). VHF radars (e.g., Hoppe and Fritts, 1995), MF radars (e.g., Manson and Meek, 1987; Fritts et al., 1998; Vincent et al., 1998) and meteor wind radars (e.g., Nakamura et al., 1996; Chang and Avery, 1997) are capable of routinely observing wind profiles in the upper mesosphere and lower thermosphere, (VHF radars only in summer). The radars have typical height resolutions of one to several $\mathrm{km}$, and time resolutions from 10 minutes to an hour. For small-scale studies of the mesosphere, and at short time scales, in-situ methods are necessary. This has been done by rocket instruments measuring trace constituents like ions or electrons (PIP, EPIP; Blix et al., 1990) and total number density (TOTAL, CONE; Giebeler et al., 1993). The rocket instrument to be described here, TROLL, measures the atmospheric total number density by Rayleigh scattering of near-infrared light. The results from this instrument are therefore independent of the ionisation state of the atmosphere.

The instrument was developed at the Norwegian Defence Research Establishment and launched on 12 October 1997 at 01:19 UT as part of the German-Norwegian rocket campaign

Copy right(C) The Society of Geomagnetism and Earth, Planetary and Space Sciences (SGEPSS); The Seismological Society of Japan; The Volcanological Society of Japan; The Geodetic Society of Japan; The Japanese Society for Planetary Sciences.
RONALD. The launch took place at Andøya Rocket Range at $69.28^{\circ} \mathrm{N}, 16.01^{\circ} \mathrm{E}$. A second instrument was launched on 31 January 1998.

In this paper, the data from the TROLL instrument will be interpreted along with ion measurements performed from the same payload, with wind measurements from a falling sphere launched 29 minutes after RONALD, and with ground-based lidar measurements of atmospheric number density from the ALOMAR RMR lidar done before, during, and after the RONALD launch.

\section{Experiment Description}

\subsection{TROLL design and performance}

Figure 1 shows a sketch of the measurement geometry. The scattering volume is determined by the divergence of the laser beam and the field of view of the detector, as well as their geometric orientation. The latter is chosen in such a way that photons scattered inside the vehicle's shock front do not reach the detector. The laser is pulsed for technical reasons, and to estimate the background signal between laser pulses, but no range information is used from the pulses. Figure 2 is a photograph of the instrument. The section is $60 \mathrm{~cm}$ long, has $44 \mathrm{~cm}$ diameter and weighs $60 \mathrm{~kg}$ (see Table 1).

The cross section for Rayleigh scatter decreases with the fourth power of the wavelength. The number of photons per Watt increases linearly with the wavelength. Therefore, the maximum number of scattered photons is achieved by maximising the product of available output power divided by the 


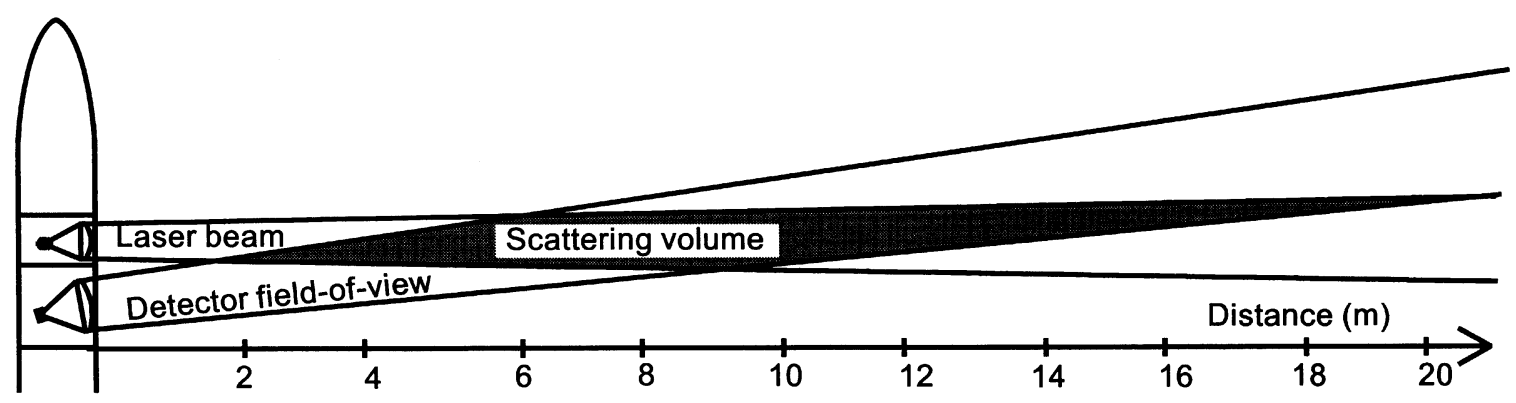

Fig. 1. Geometry of rocket-borne lidar instrument. The scattering volume is the geometric overlap between the laser beam and the detector field of view.

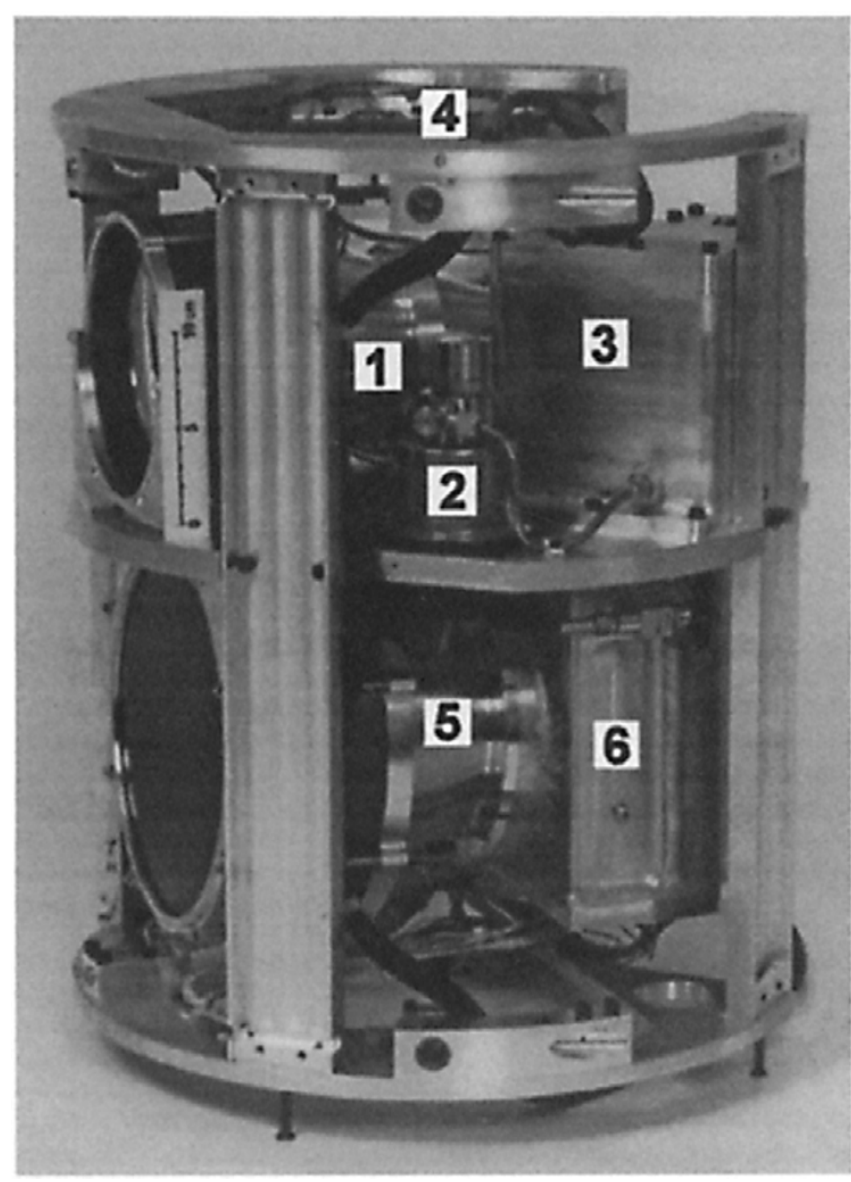

Fig. 2. The TROLL instrument: 1. Transmitter collimating lens. 2. Circulation pump. 3. Coolant container. 4. Laser power-supply. 5. Receiver lens. 6. Avalanche photodiode detector housing.

third power of the wavelength. At the time of purchase, a diode laser array near $800 \mathrm{~nm}$ was near the maximum of this parameter. Typical airglow spectra have an intensity of 50-70 Rayleigh/nm at $800 \mathrm{~nm}$, and typical aurora 150-700 Rayleigh/nm (Taylor and Henriksen, 1989). Both airglow and auroral spectra have a local minimum at $800 \mathrm{~nm}$, compared to the $780 \mathrm{~nm}-820 \mathrm{~nm}$ that were available as laser wavelengths. The instrument was designed for background light levels of 300 Rayleigh/nm, therefore there should not be strong aurora at the time of launch, and the moon should be below the horizon, as viewed from the upper cloud surface

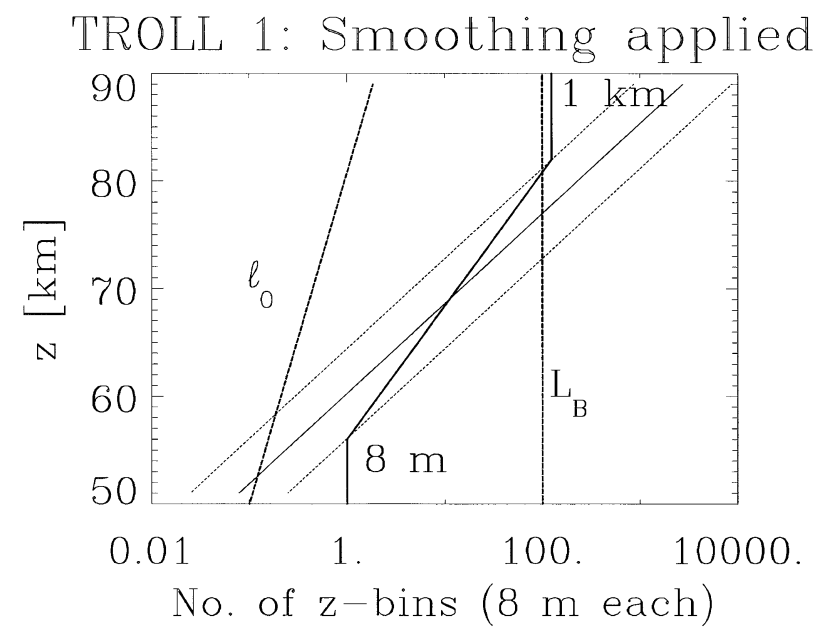

Fig. 3. The vertical smoothing necessary to achieve a given number density precision. The thick, stepped line between $8 \mathrm{~m}$ and $1 \mathrm{~km}$ shows the smoothing that was applied to the data used in this paper. The full, slanted line shows the smoothing that is necessary to achieve a $1 \%$ precision in number density, the dotted line below is for $0.1 \%$ and the dotted line above for $10 \%$ precision, respectively. Typical profiles of the buoyancy scale $L_{B}$ and the inner scale $1_{0}$ are shown for reference.

or from ground level. Furthermore, the sun must not directly illuminate the instrument at any time, that is, the sun must be below the horizon viewed from apogee.

Laboratory calibrations showed that the standard deviation of absolute number density is $4.2 \cdot 10^{19} \mathrm{~m}^{-3}$ at all heights. This is the atmospheric number density near $93 \mathrm{~km}$ (signal to noise $\approx 1$; standard deviation of relative number density $=100 \%$ ). At $56 \mathrm{~km}$, the standard deviation is $10^{-3}=0.1 \%$ of the total number density. This number was confirmed from the actual atmospheric observations. After the removal of datapoints that were obviously influenced by microphonics in the payload or other interference ( $<4 \%$ of the data points), the distribution of differences between adjacent datapoints was approximately Gaussian with a standard deviation of $4.2 \cdot 10^{19} \mathrm{~m}^{-3}$.

As the number density uncertainty can be improved by averaging over several samples, there is a trade-off between height resolution and density resolution. Figure 3 shows the vertical smoothing necessary to achieve a given standard deviation of the relative number density, $1 \%$ as a solid line and $0.1 \%$ and $10 \%$ as dotted lines. Representative values for 
Table 1. Instrument characteristics.

\begin{tabular}{|c|c|}
\hline \multicolumn{2}{|l|}{ Physical dimensions } \\
\hline Section length & $60 \mathrm{~cm}$ \\
\hline Section diameter & $43.8 \mathrm{~cm}$ \\
\hline Section mass & $60 \mathrm{~kg}$ \\
\hline Transmitter & 20-bar stacked-array diode laser \\
\hline Peak output power & $500 \mathrm{~W}$ \\
\hline Pulse length & $459 \mu \mathrm{s}$ \\
\hline Pulse rep rate & $135 \mathrm{~Hz}$ \\
\hline Duty cycle & $6.2 \%$ \\
\hline Average power & $31 \mathrm{~W}$ \\
\hline Wavelength & $805 \mathrm{~nm}$ \\
\hline Bandwidth & $>90 \%$ of energy within $\pm 4 \mathrm{~nm}$ \\
\hline Divergence after collimation & $\pm 4.2^{\circ}$ \\
\hline \multicolumn{2}{|l|}{ Receiver } \\
\hline Detector & Large-area avalanche photodiode \\
\hline Detector diameter & $10 \mathrm{~mm}$ \\
\hline Quantum efficiency & $80 \%$ \\
\hline Responsitivity & $0.52 \mathrm{~A} / \mathrm{W}$ \\
\hline Gain & 200 \\
\hline Dark current at $-20^{\circ} \mathrm{C}$ & $2 \cdot 10^{-9} \mathrm{~A}$ \\
\hline NEP & $3.8 \cdot 10^{-19} \mathrm{~W} / \mathrm{Hz}^{0.5}$ \\
\hline Objective diameter & $20 \mathrm{~cm}$ \\
\hline f-number & 1.16 \\
\hline Field of view & $\pm 1.3^{\circ}$ \\
\hline Interference filter bandwidth & $10 \mathrm{~nm}$ \\
\hline Range to scattering volume & $2 \mathrm{~m}$ \\
\hline \multicolumn{2}{|l|}{ Trajectory } \\
\hline Spin rate & $0.1 \mathrm{~s}^{-1}$ \\
\hline Apogee & $121 \mathrm{~km}$ \\
\hline Nominal observation range & $50 \mathrm{~km}$ to apogee \\
\hline Velocity at $50 \mathrm{~km}$ & $1200 \mathrm{~m} / \mathrm{s}$ \\
\hline Velocity at $75 \mathrm{~km}$ & $950 \mathrm{~m} / \mathrm{s}$ \\
\hline Sample spacing at $50 \mathrm{~km}$ & $8.9 \mathrm{~m}$ \\
\hline Sample spacing at $75 \mathrm{~km}$ & $7 \mathrm{~m}$ \\
\hline \multicolumn{2}{|l|}{ Performance } \\
\hline Single-sample error bar & $4.2 \cdot 10^{19} \mathrm{~m}^{-3}$ \\
\hline Observation range this analysis & $52 \mathrm{~km}$ to $>75 \mathrm{~km}$ \\
\hline Possible observation range & $20 \mathrm{~km}$ to $92 \mathrm{~km}$ \\
\hline
\end{tabular}


Table 2. RMR Lidar instrument parameters.

\begin{tabular}{|c|c|}
\hline Transmitter & \\
\hline \multicolumn{2}{|c|}{1 single-mode cw Nd:YAG seeder laser: } \\
\hline & Spectral stability better than $10^{-8}$ at $532 \mathrm{~nm}$ by iodine absorption spectroscopy \\
\hline \multicolumn{2}{|c|}{2 injection seeded pulsed Nd:YAG power lasers: } \\
\hline & Repetition rate $30 \mathrm{~Hz}$ \\
\hline & Spectral width $<70 \mathrm{MHz}$ at $532 \mathrm{~nm}$, \\
\hline & Beam pointing stability $<20$ (rad for each axis before beam widening, \\
\hline & Beam diameter $200 \mathrm{~mm}$ with full divergence $<100 \mu \mathrm{rad}$ after beam widening. \\
\hline \multicolumn{2}{|l|}{ Wavelengths: } \\
\hline & $1064 \mathrm{~nm}$, pulse power/energy/width $11.0 \mathrm{~W} / 360 \mathrm{~mJ} / 15 \mathrm{~ns}$, \\
\hline & Elliptically polarised \\
\hline & $532 \mathrm{~nm}$, pulse power/energy/width $12.0 \mathrm{~W} / 400 \mathrm{~mJ} / 12 \mathrm{~ns}$, \\
\hline & Horizontally polarised \\
\hline & $355 \mathrm{~nm}$, pulse power/energy/width $6.5 \mathrm{~W} / 215 \mathrm{~mJ} / 10 \mathrm{~ns}$, \\
\hline \multicolumn{2}{|c|}{ Vertically polarised } \\
\hline \multicolumn{2}{|l|}{ Telescopes } \\
\hline \multicolumn{2}{|c|}{2 quasi-Cassegrain telescopes: } \\
\hline & Diameter $180 \mathrm{~cm}$, field-of-view $<180 \mu \mathrm{rad}$ full angle \\
\hline 1 telescope: & Diameter $60 \mathrm{~cm}$, field-of-view 190-560 $\mu \mathrm{rad}$, optional, full angle \\
\hline 1 telescope: & Diameter $50 \mathrm{~cm}$ \\
\hline \multicolumn{2}{|l|}{ Detectors } \\
\hline \multicolumn{2}{|c|}{12 RMR channels in photon counting mode: } \\
\hline \multicolumn{2}{|c|}{ Detected wavelengths: the same as emitted at $1064,532,355 \mathrm{~nm}$} \\
\hline & Vibrational Raman lines for $\mathrm{N} 2$ at $387,607 \mathrm{~nm}$ \\
\hline & Vibrational Raman line for $\mathrm{H} 2 \mathrm{O}$ at $660 \mathrm{~nm}$ \\
\hline & Rotational Raman lines for air at $529.1,530.4 \mathrm{~nm}$ \\
\hline Spectral widths: & $\approx 10 \mathrm{pm}$ at $1064 \mathrm{~nm}, \approx 4 \mathrm{pm}$ at $532 \mathrm{~nm}, \approx 4 \mathrm{pm}$ at $355 \mathrm{~nm}$ \\
\hline Resolution: & $150 \mathrm{~m}$ in altitude, $167 \mathrm{~s}$ in time \\
\hline 1 Doppler wind a & erature system (DWTS) channel at $532 \mathrm{~nm}$ \\
\hline
\end{tabular}

the buoyancy scale $L_{B}$ and the inner scale $1_{0}$ are also shown for reference. Below $56 \mathrm{~km}$, the error bar is smaller than $0.1 \%$ even for single samples without smoothing. For the analysis presented in this paper, we have chosen to consider only height resolutions up to $1 \mathrm{~km}$. We have therefore smoothed our data as shown by the thick solid line, with no smoothing below $56 \mathrm{~km}$, and smoothing over 125 samples above $82 \mathrm{~km}$. The smoothing was realised with a non-recursive low-pass digital filter with the number of terms adapted to the varying value of the cut-off frequency.

The background is sampled 15 times between laser pulses. The background during each laser pulse is estimated from a linear regression of the background measured before and after each pulse. Although the raw data contains significant airglow signal each time the detector is looking horizontally (once every $5 \mathrm{~s}$ ), this background is precisely subtracted by our algorithm.

The output power of the laser is monitored by a photodiode staring at the emitting surface from the edge of the cone of light transmitted.

A detailed technical description of the instrument is given by Eriksen et al. (1999).

\subsection{Electrostatic skin probes}

Two electrostatic skin probes were flown on the RONALD rocket payload. One measured electrons, the other positive ions. Both probes consisted of a circular plate collector with a diameter of $6 \mathrm{~cm}$ and an outer guard ring with a width of $4 \mathrm{~mm}$ and an outer diameter of $7.5 \mathrm{~cm}$. The electron probe collector and the guard ring were biased by $+6 \mathrm{~V}$ with respect to the payload skin (floating potential) while the ion collector and 


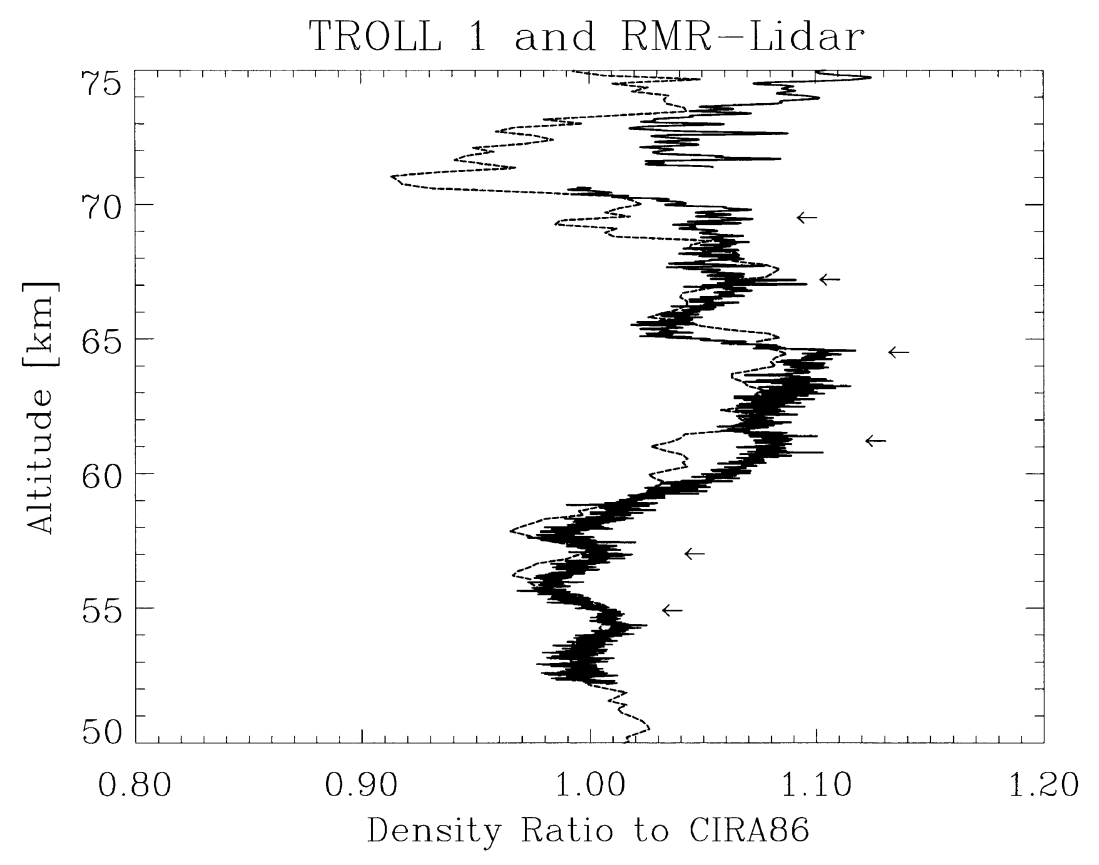

Fig. 4. Observed relative number density profile from TROLL and from the ALOMAR RMR lidar. Heavy line: TROLL 1, 12.10.97 01:19 UT, upleg. Dashed line: RMR-lidar 00:50-01:50 UT. Arrows refer to discussion in Section 4, Table 3, and Fig. 8, below.

guard ring were biased by $-6 \mathrm{~V}$. The guard ring is necessary in order to have a well-defined electric field configuration in front of the collector plate. Both probes were mounted flush with the skin of the payload such that the supersonic plasma flow around the payload was directed approximately $90^{\circ}$ to the collecting electric field of the probes. This configuration has to our knowledge not been flown before, but calibration tests were performed in the plasma chamber at the Norwegian Defence Research Establishment prior to launch. In this paper we will use the measured current directly to compare relative ion density with the neutral density measured by the TROLL experiment. The sampling frequency of both probes was $2170 \mathrm{~Hz}$, giving a spatial resolution of better than about $0.5 \mathrm{~m}$, taking into account the vehicle velocity, which was nearly $1000 \mathrm{~m} / \mathrm{s}$ in the altitude range of interest. The electron probe was designed to measure a current in the range $5 \cdot 10^{-11} \mathrm{~A}$ to $5 \cdot 10^{-5} \mathrm{~A}$, and the ion probe in the range $5 \cdot 10^{-11}$ A to $5 \cdot 10^{-6} \mathrm{~A}$. Both probes had automatic gain control between $1 \times$ and $1000 \times$ in steps of 10 and a 14-bit ADC. In addition, 2 bits were used for range indication.

\subsection{ALOMAR Rayleigh/Mie/Raman lidar}

The ALOMAR Rayleigh/Mie/Raman lidar (RMR lidar) is part of the ALOMAR facility (Thrane and von Zahn, 1995; von Zahn, 1997) at Andøya $\left(69.28^{\circ} \mathrm{N}, 16.01^{\circ} \mathrm{E}\right)$ in Northern Norway and has been developed and is being operated jointly by research groups from Germany, the United Kingdom and France. The system was designed for long-term observations of the Arctic middle atmosphere on a climatological basis in the altitude range from 10 to $90 \mathrm{~km}$. To obtain as many atmospheric measurements as possible, the RMR lidar is used in a routine observation mode. In June 1994 the RMR lidar collected the first atmospheric data and since January 1995 it has been in routine operation.

For a more detailed description of special system features, see Table 2, Fiedler et al. (1997), Rees et al. (1997) and Fiedler and von Cossart (1998).

The air density and temperature profiles used in this paper have been obtained from the RMR channels at $532 \mathrm{~nm}$.

\subsection{Falling sphere}

The falling sphere technique has been described in the literature (Schmidlin, 1991; Lübken et al., 1994). The sphere, made of metallised mylar, is typically released at $110 \mathrm{~km}$ altitude and inflated to $1 \mathrm{~m}$ diameter. It passively falls in the atmosphere, and its descent trajectory is tracked by a highprecision radar. From the radar-determined position the first and second derivatives of the sphere trajectory with respect to time are obtained, which are then used in the equations of motion to determine atmospheric density and horizontal winds. Temperatures are obtained by integrating the density profile assuming hydrostatic equilibrium.

\section{Observed Profile of Neutral Number Density}

Figure 4 shows the ratio of observed number density to model number density from our instrument in the full line with the greatest height resolution. The smallest-scale fluctuations by about $\pm 0.1 \%$ are due to the instrumental noise described above. CIRA 1986 was chosen as a model simply to emphasise variations from an established reference profile. For this purpose, it does not matter if CIRA 1986 describes a good climatological mean at high latitudes or not (Lübken and von Zahn, 1991). The observed profile clearly shows the height resolution decreasing at greater heights due to the filtering described above. The dashed profile is from the ground-based ALOMAR RMR lidar, where the data has been integrated for one hour centred on the time of launch. There is surprisingly good agreement between the profiles measured by the rocket instrument and the ground-based instrument, given the following differences in observing con- 


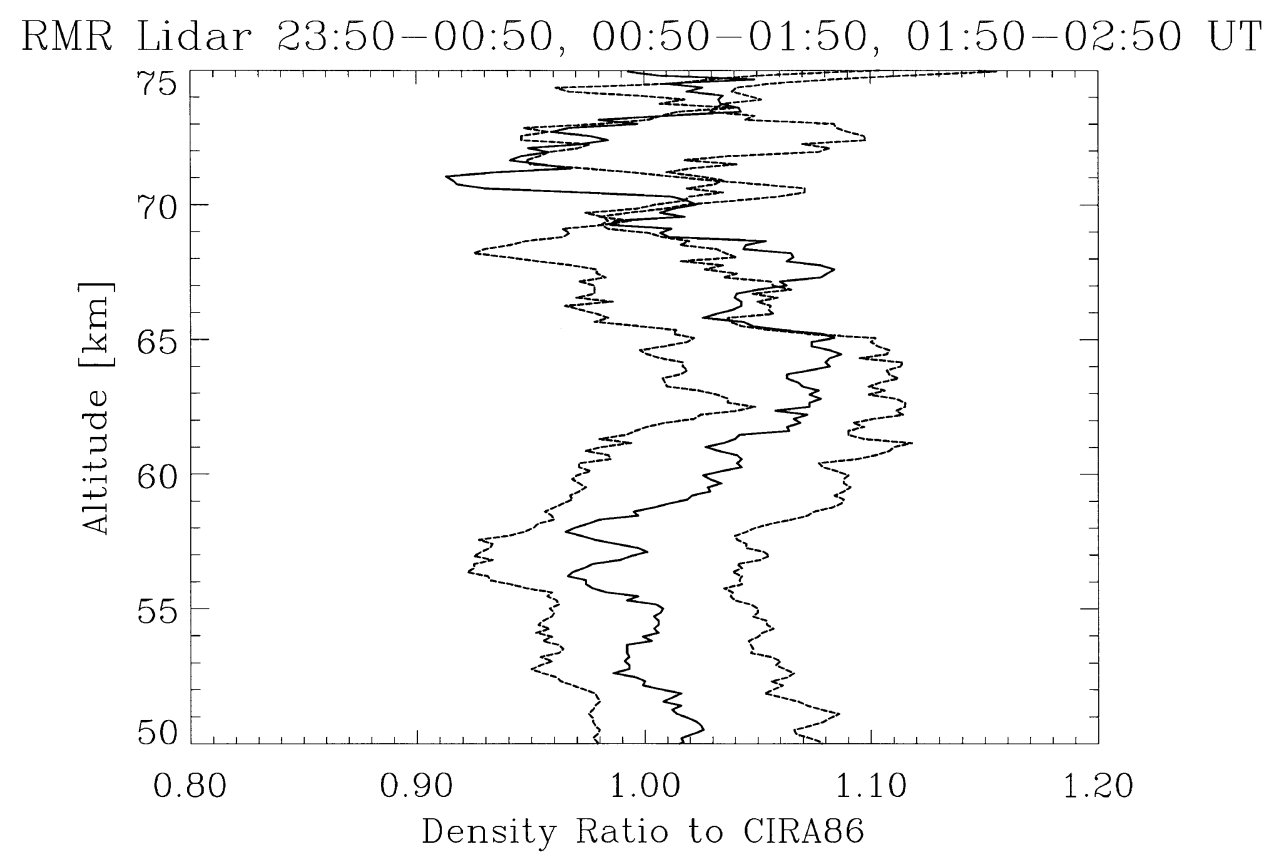

Fig. 5. RMR lidar profile during launch, as Fig. 4, solid line. RMR lidar profiles from the preceding and succeeding hours, dotted lines. The latter two have been displaced by -0.05 and +0.05 , respectively, for clarity.

ditions: The rocket instrument TROLL observed during a 25-s time interval along a trajectory located approximately $14 \mathrm{~km}$ north of ALOMAR and the ALOMAR profile is averaged for one hour. The deviations by $2 \%$ near $61 \mathrm{~km}$ and by $6 \%$ at $69 \mathrm{~km}$ and $10 \%$ near $71 \mathrm{~km}$ may be due to the differences in space and time in the presence of (assumed) slowly propagating waves, as is suggested by the ALOMAR RMR profiles from the hour before and after (Fig. 5).

Neither the ALOMAR RMR lidar nor the TROLL instrument are calibrated precisely enough to give an absolute number density profile. Therefore, the relative number density profiles are normalised to a standard atmosphere at one height. We use the COSPAR International Reference Atmosphere (CIRA). The standard calibration height used for the RMR lidar is $40 \mathrm{~km}$. The TROLL instrument could not measure as low as that, so we chose $52.5 \mathrm{~km}$ as a calibration height, where the RMR lidar profile happened to be equal to the CIRA value at that time. The absolute agreement between the RMR and TROLL number density profiles is due to this calibration, but the agreement in height and relative change of the variations is of geophysical significance. It shows that the observed density structures persist for a time period of an hour or more, and that their horizontal scale is greater than some tens of $\mathrm{km}$.

\section{Discussion}

The observed relative number density profile from TROLL is expanded in Fig. 6. The full lines marked $\Gamma$ show the relative density profile for an adiabatic lapse rate. If the relative density were to increase with height faster than shown by this line, the atmosphere would be statically unstable. These gradients have been determined as the ratio of the density gradient of the adiabatic lapse rate at the actual temperature (from the RMR lidar) to the density gradient of the adiabatic lapse rate in CIRA86. At $57 \mathrm{~km}$, the choice of density ratio to CIRA as a coordinate leads to the curious fact that $\Gamma$ is more negative than CIRA. The reason is that the actual temperature at this height was larger than CIRA. Note that the actual adiabatic lapse rate or its density gradient do not depend on CIRA at all, we only need CIRA to identify unstable regions in this plot. Areas of very stable layering with

$$
\frac{\partial(\text { density ratio })}{\partial z}<0
$$

are separated by areas of metastable layering

$$
\left(\frac{\partial(\text { density ratio })}{\partial z}\right) \cong \Gamma \text {. }
$$

Intermediate gradients exist only at few heights. One possible interpretation is that a number of turbulent regions (or regions that have recently been mixed by turbulence) are interspersed with very stable layers. Turbulence would drive the density gradient towards the adiabatic gradient. Then very stable gradients would be required to connect the gradient in the turbulent regions to the average background gradient.

From measuring the relative vertical distances in Fig. 6 between maxima, minima, and maxima and minima of the gradient, respectively, another possible interpretation can be proposed: Figure 6 may show the signature of a saturated gravity wave of approximately $5 \mathrm{~km}$ vertical wavelength (3 $\mathrm{km}$ below $58 \mathrm{~km}, 6 \mathrm{~km}$ above). Due to the saturation, the relative density profile is sawtooth-shaped instead of harmonic. In order to test this last hypothesis, we have plotted the horizontal wind data from a falling sphere launched at 01:48:00 UT in hodograph format (Fig. 7). The wind profile below $50 \mathrm{~km}$ is a fairly regular clockwise spiral (not shown here), as expected for a non-saturated gravity wave. From 


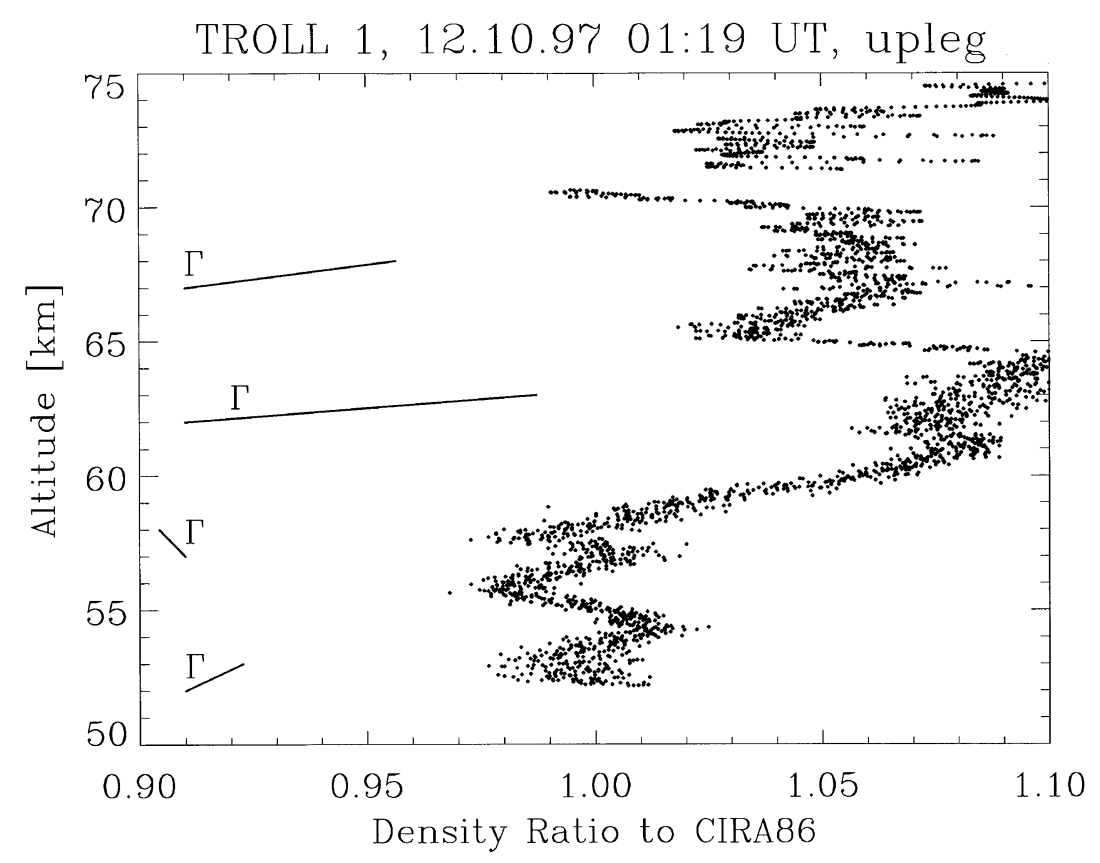

Fig. 6. Expanded relative number density profile with alternating stable and metastable layers.

$50 \mathrm{~km}$ to $53 \mathrm{~km}$ and from $67 \mathrm{~km}$ to $70 \mathrm{~km}$, we also see pieces of a regular, clockwise spiral, which is stretched WSW to ENE. The spiral contains nearly one full rotation from 50 $\mathrm{km}$ to $53 \mathrm{~km}$, lending independent support to the $3-\mathrm{km}$ vertical wavelength proposed from the TROLL data. The ratio of the axes of the spiral is approximately two to one. Between $53 \mathrm{~km}$ and $67 \mathrm{~km}$, the spiral has been distorted with at least four changes of the sense of rotation. The zonal wind component is close to $60 \mathrm{~m} / \mathrm{s}$ in this whole height region. The metastable height regions from Fig. 6 are marked as thick lines in Fig. 7. Note that the height regions most distorted from a spiral are metastable in Fig. 6. Note also that all of these height regions have a zonal wind of approximately 60 $\mathrm{m} / \mathrm{s}$, independent of the meridional wind. A possible interpretation is that a wave with a phase speed of approximately $60 \mathrm{~m} / \mathrm{s}$ towards eastnortheast is interacting with the background mean flow, accelerating the mean flow towards that value. More work is needed to verify these hypotheses.

We now turn to another aspect of the TROLL data: The height regions near $69.6 \mathrm{~km}, 67.3 \mathrm{~km}, 64.6 \mathrm{~km}, 61.3 \mathrm{~km}, 57.2$ $\mathrm{km}$, and $55 \mathrm{~km}$ are shown by arrows in Fig. 4 . The six panels of Fig. 8 show the ion current measured with the skin probes in the same height ranges. Note that we have pronounced enhancements of the ion density in the stably stratified regions (negative gradient of density ratio to CIRA), except at $55 \mathrm{~km}$. We have other stably stratified height regions where we do not observe ion density enhancements. If there is an ion layering mechanism at work at a given height, the layer will be destroyed by turbulence if the atmosphere is unstable, but the layer can build up where the atmosphere is stable. Evidently we need both a layering mechanism and a stable atmosphere to create ion enhancements. Assuming that the wind shear in the geomagnetic field is generating the ion layers (as in a sporadic-E layer), we have listed the

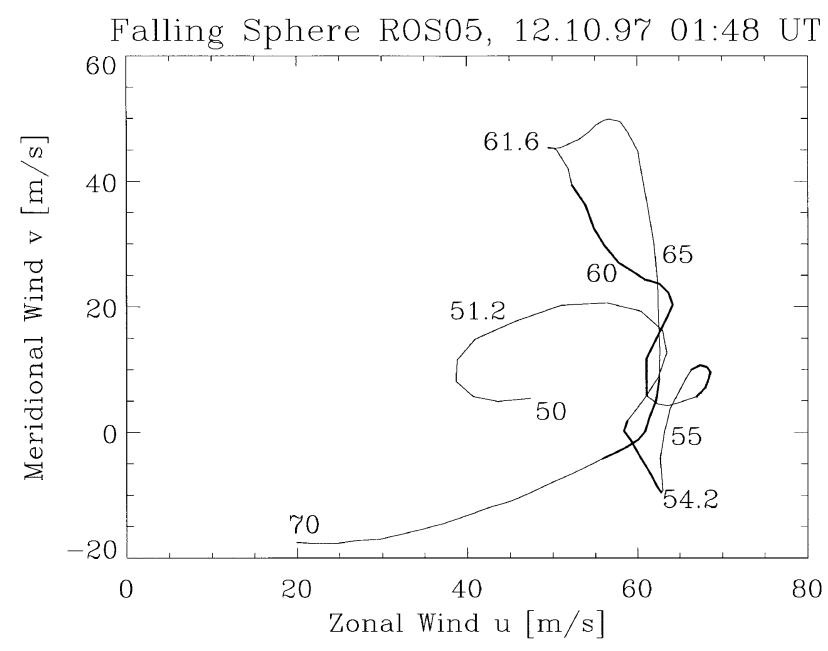

Fig. 7. Hodograph of horizontal wind observed by falling sphere 29 minutes after RONALD launch. Altitude is given in $\mathrm{km}$ next to the graph. The thicker lines correspond to the (nearly) unstable regions identified in Fig. 6: $52.9-54.35 \mathrm{~km}, 55.65-57.2 \mathrm{~km}, 57.6-61.0,65.52-67.1 \mathrm{~km}$.

stable layers from Fig. 6 and the presence or absence of ion maxima with the zonal wind gradient (Fig. 8) in Table 3. The zonal wind is positive (towards east) in the complete height region. With the northward component of the geomagnetic field, this wind will drive positive ions upward. Where the zonal wind decreases with height ( $d u / d z$ negative), positive ions are driven upward less at greater heights, concentrating them in a layer. We find five cases out of six that agree with the assumptions made. The disagreement at $64.6 \mathrm{~km}$ is small, as the zonal wind gradient is small. It is much more likely for the wind gradient to change from a negative value to $+0.5 \mathrm{~m} \mathrm{~s}^{-1} \mathrm{~km}^{-1}$ within the 29 minutes between the 


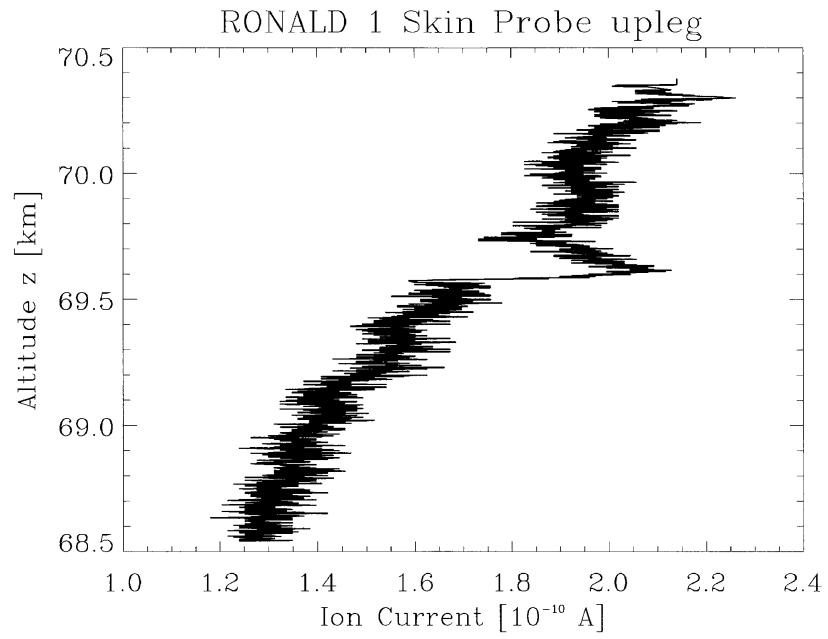

(a)

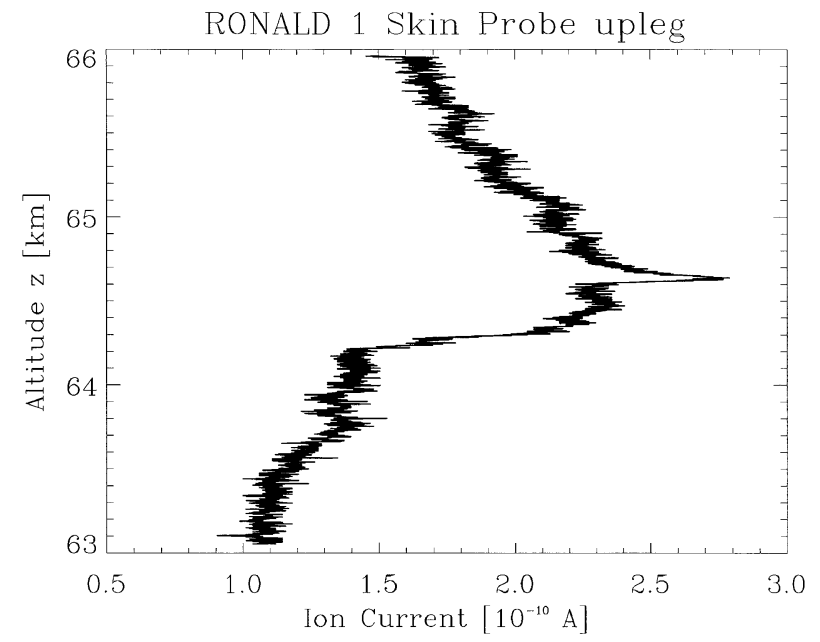

(c)

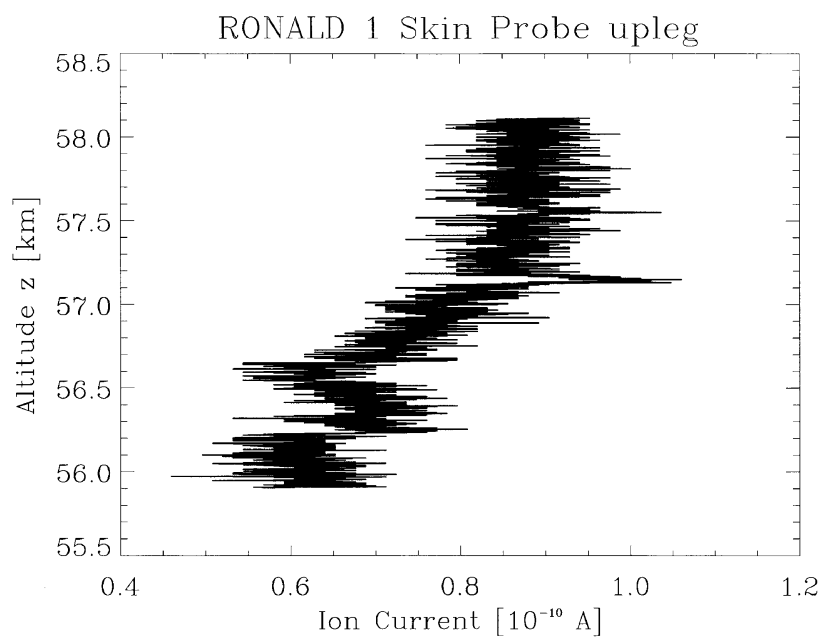

(e)

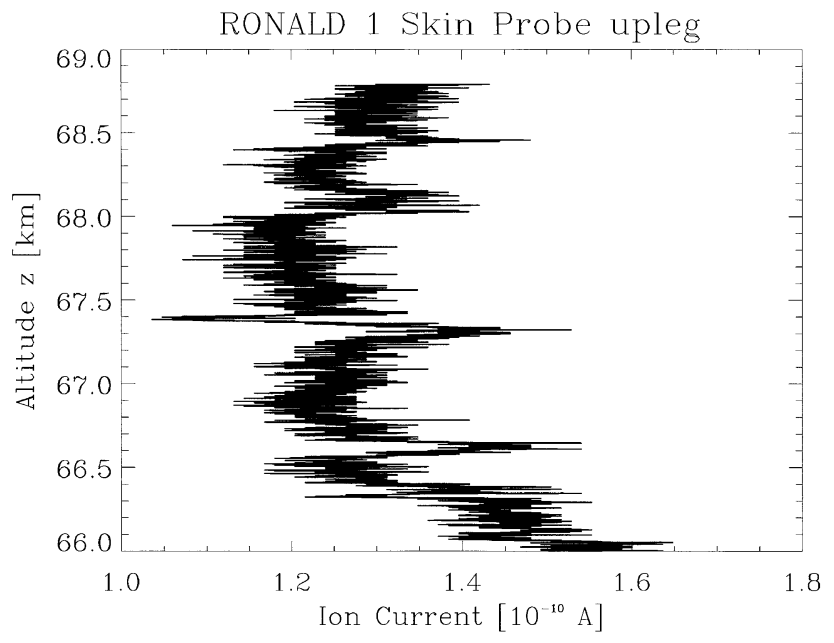

(b)

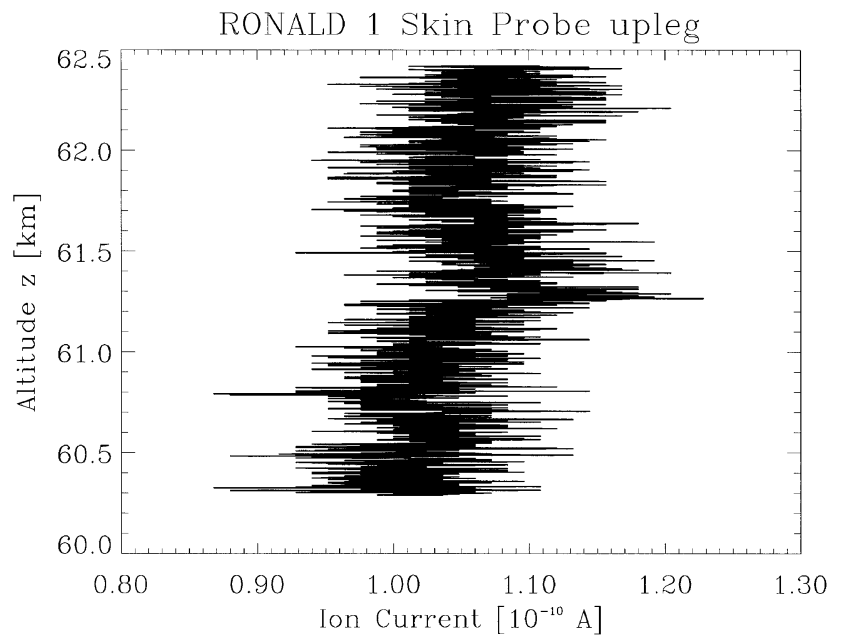

(d)

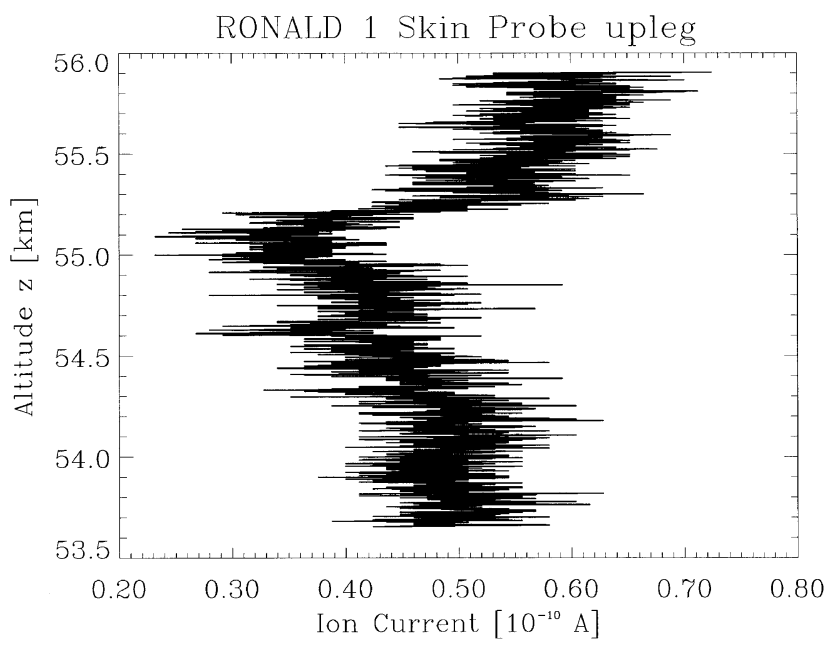

(f)

Fig. 8. Ion current to the skin probe near $69.6 \mathrm{~km}$ (a), $67.3 \mathrm{~km}$ (b), $64.6 \mathrm{~km}$ (c), $61.3 \mathrm{~km}$ (d), $57.1 \mathrm{~km}$ (e), and $55 \mathrm{~km}$ (f). 
Table 3. Ion layering truth table.

\begin{tabular}{cccc}
\hline Stable region & Ion maximum & $d u / d z$ & Agreement \\
\hline $69.6 \mathrm{~km}$ & yes & $-11 \mathrm{~m} \mathrm{~s}^{-1} \mathrm{~km}^{-1}$ & yes \\
$67.3 \mathrm{~km}$ & yes & $-10 \mathrm{~m} \mathrm{~s}^{-1} \mathrm{~km}^{-1}$ & yes \\
$64.6 \mathrm{~km}$ & yes & $+0.5 \mathrm{~m} \mathrm{~s}^{-1} \mathrm{~km}^{-1}$ & no \\
$61.3 \mathrm{~km}$ & yes & $-3 \mathrm{~m} \mathrm{~s}^{-1} \mathrm{~km}^{-1}$ & yes \\
$57.2 \mathrm{~km}$ & yes & $-6 \mathrm{~m} \mathrm{~s}^{-1} \mathrm{~km}^{-1}$ & yes \\
$55.0 \mathrm{~km}$ & no & $+3 \mathrm{~m} \mathrm{~s}^{-1} \mathrm{~km}^{-1}$ & yes \\
\hline
\end{tabular}

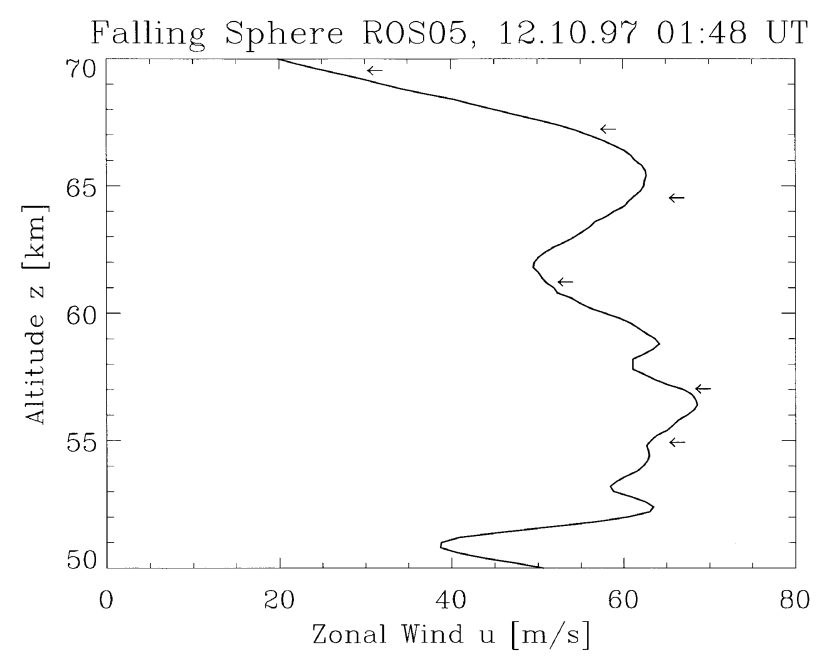

Fig. 9. Zonal wind profile from falling sphere. The arrows mark the heights in Table 3 and Fig. 8.

RONALD launch and the falling sphere than to change sign from any of the other values in Table 3. Alternatively, there could be an uncertainty of $0.7-1 \mathrm{~m} \mathrm{~s}^{-1} \mathrm{~km}^{-1}$ in the observed wind gradients. Figures 8(b) and (d) show three and one other small enhancements of ion density, respectively, that we do not have an explanation for.

Obviously, the influence of the dynamic processes on the temporal and spatial variations in the plasma depends on the lifetimes of the ions and electrons relative to the dynamic time scales. This problem has been treated in some detail by Fritts and Thrane (1990) and by Thrane et al. (1994). We can make a rough estimate of the ion lifetime in the lower Dregion during the RONALD flight. The continuity equation for positive ions in the D-region may be written:

$$
\frac{d \mathrm{~N}_{+}}{d t}=q-\frac{\alpha_{\mathrm{D}}+\lambda \alpha_{\mathrm{i}}}{1+\lambda} \mathrm{N}_{+}^{2}=q-\alpha_{\mathrm{effi}} \mathrm{N}_{+}^{2}
$$

where $q$ is the ion production, $\lambda=\mathrm{N}_{-} / n_{\mathrm{e}}$ the ratio of negative ion density to electron density, $\alpha_{\mathrm{D}}$ the dissociative recombination coefficient for water cluster ions, $\alpha_{\mathrm{i}}$ the ion-ion recombination rate and $\alpha_{\text {effi }}$ the effective recombination rate. The average lifetime of an ion is then $\tau=1 /\left(2 \alpha_{\text {effi }} \mathrm{N}_{+}\right)$. We choose the following representative values, based upon published values of $\lambda, \alpha_{\mathrm{D}}$ and $\alpha_{\mathrm{i}}$, as well as the ion current measurements by the skin probes, this time combined with the laboratory calibration of these probes:

$\begin{array}{lll}\lambda(60 \mathrm{~km}) & 1000 & \text { Torkar et al., } 1981 \\ \lambda(70 \mathrm{~km}) & 100 & \text { Torkar } \text { et al., } 1981 \\ \mathrm{~N}_{+}(60 \mathrm{~km}) & 5 \cdot 10^{7} \mathrm{~m}^{-3} & \text { Skin probe } \\ \mathrm{N}_{+}(70 \mathrm{~km}) & 3 \cdot 10^{8} \mathrm{~m}^{-3} & \text { Skin probe } \\ \alpha_{\mathrm{D}} & 3 \cdot 10^{-12} \mathrm{~m}^{3} \mathrm{~s}^{-1} & \text { Torkar and Friedrich, } 1988 \\ \alpha_{\mathrm{i}} & 5 \cdot 10^{-14} \mathrm{~m}^{3} \mathrm{~s}^{-1} & \text { Conley, 1974 }\end{array}$

With these values, the typical lifetime of a positive ion is $200,000 \mathrm{~s}$ at $60 \mathrm{~km}$ and $20,000 \mathrm{~s}$ at $70 \mathrm{~km}$, respectively. This lifetime should be sufficiently long to collect the ions in a thin layer, provided that molecular diffusion does not redistribute the ions with a shorter time constant. The typical time constant for molecular diffusion is

$$
\tau_{m}=\frac{L^{2}}{v}
$$

where $L$ is a length scale and $v$ the kinematic viscosity. At $70 \mathrm{~km}$ and for a layer thickness of $100 \mathrm{~m}$ the time constant is $\tau_{m} \approx 6 \cdot 10^{4} \mathrm{~s}$

\section{Summary}

The rocket instrument presented here, TROLL, measures total atmospheric density with great precision and resolution. Comparison with a ground-based lidar shows:

(a) both instruments measure the same physical parameters, even though they have different integration times and integration volumes.

(b) The observed density structures change little over the course of an hour and the horizontal distance of $14 \mathrm{~km}$.

The rocket instrument has a basic vertical resolution of approximately $8 \mathrm{~m}$ and a number density precision of $4.2 \cdot 10^{19}$ $\mathrm{m}^{-3}$. Above $56 \mathrm{~km}$ we integrate over an increasing vertical range, reaching $80 \mathrm{~m}$ at $70 \mathrm{~km}$. The measured number density profile shows remarkable alternations between very stable layering and metastable layering (adiabatic lapse rate) in the atmosphere between $52 \mathrm{~km}$ and $71 \mathrm{~km}$. Comparison with the hodograph of the horizontal wind profile measured by a falling sphere 29 minutes later shows that the metastable height regions coincide with height regions where the hodograph deviates from an ideal spiral. We tentatively interpret this observation as a gravity wave that is saturating (or encountering a critical level) in these height regions. The comparison of the fine-scale neutral number density observations with measurements of ion density by skin probes on board the same vehicle shows a number of ion density 
enhancements in the stably-layered height regions. A truth table is shown testing the following hypothesis: "An ion density enhancement occurs every time the atmosphere is stably layered and the horizontal wind gradient supports the windshear/geomagnetic mechanism for sporadic E layers." The one disagreement out of six cases that we find has a very small vertical gradient of the zonal wind of the wrong sign, and may be due to changes in the wind profile over the 29 minutes. This may be the first observation of such ion density enhancements in the height region 55 to $70 \mathrm{~km}$.

Acknowledgments. We are grateful to the personnel at Andøya Rocket Range for their professional launch service and precise trajectory and orientation information. The project was funded by the Research Council of Norway. UPH thanks D. C. Fritts for valuable discussion of the data. He also thanks the organisers and participants of the DYSMER symposium for the stimulating meeting. JF thanks Reidar Lyngra for operating the ALOMAR RMR lidar during the campaign. JF also thanks U. von Zahn, one of the initiators of the ALOMAR research facility, for his special support concerning the development and operation of the ALOMAR RMR lidar.

\section{References}

Blix, T. A., E. V. Thrane, and Ø. Andreassen, In-situ measurements of the fine-scale structure and turbulence in the mesosphere and lower thermosphere by means of electrostatic positive ion probes, J. Geophys. Res., 95(D5), 5533-5548, 1990.

Chang, J. L. and S. K. Avery, Observations of the diurnal tide in the mesosphere and lower thermosphere over Christmas Island, J. Geophys. Res., 102(D2), 1895-1907, 1997.

Conley, T. D., Mesospheric positive ion concentrations, mobilities, and loss rates obtained from rocket-borne Gerdien condenser measurements, $R a$ dio Sci., 9(6), 575-592, 1974.

Eriksen, T., U.-P. Hoppe, E. V. Thrane, and T. A. Blix, Rocketborne Rayleigh lidar for in-situ measurements of neutral atmospheric density, Appl. Opt., 38(12), 2605-2613, 1999.

Fiedler, J. and G. von Cossart, Automated Lidar Transmitter for MultiParameter Investigations within the Arctic Atmosphere, IEEE Trans. Geosci. Remote Sensing, 37, 748-755, 1999.

Fiedler, J., G. von Cossart, F. Hübner, H. Mehrtens, U. von Zahn, K.H. Fricke, G. Nelke, A. Hauchecorne, F. Fierli, and D. Rees, Status of the ALOMAR Rayleigh/Mie/Raman Lidar, in Proc. 13th ESA Symposium on European Rocket and Balloon Programmes \& Related Research (Öland/Sweden), ESA SP-397, pp. 105-110, 1997.

Fritts, D. C. and E. V. Thrane, Computation of the ion/neutral density ratio in the presence of wave and chemical effects, J. Atmos. Terr. Phys., 52(10/11), 827-834, 1990.

Fritts, D. C., D. M. Riggin, B. B. Balsley, and R. G. Stockwell, Recent results with an MF radar at McMurdo, Antarctica: Characteristics and variability of motions near 12-hour period in the mesosphere, Geophys. Res. Lett., 25(3), 297-300, 1998.

Giebeler, J., F. J. Lübken, and M. Nägele, CONE-A new sensor for insitu observations of neutral and plasma density fluctuations, in Proc. 11th ESA Symposium on European Rocket and Balloon Programmes \& Related Research (Montreux, Switzerland), ESA SP-355, pp. 311-318, 1993.

Hoppe, U.-P. and D. C. Fritts, High-resolution measurements of vertical velocity with the European incoherent scatter VHF radar, 1. Motion field characteristics and measurement biases, J. Geophys. Res., 100(D8), 16,813-16,825, 1995.

Lübken, F.-J. and U. von Zahn, Thermal structure of the mesopause region at polar latitudes, J. Geophys. Res., 96(D11), 20,841-20,857, 1991.

Lübken, F.-J., W. Hillert, G. Lehmacher, U. von Zahn, M. Bittner, D. Offermann, F. Schmidlin, A. Hauchecorne, M. Mourier, and P. Czechowsky, Intercomparison of density and temperature profiles obtained by lidar, ionisation gauges, falling spheres, datasondes and radiosondes during the DYANA campaign, J. Atmos. Terr. Phys., 56(13/14), 1969-1984, 1994.

Manson, A. H. and C. E. Meek, Small-scale features in the middle atmosphere wind field at Saskatoon, Canada $\left(52^{\circ} \mathrm{N}, 107^{\circ} \mathrm{W}\right)$ : An analysis of MF radar data with rocket comparisons, J. Atmos. Sci., 44, 3661-3672, 1987.

Nakamura, T., T. Tsuda, and S. Fukao, Mean winds at $60-90 \mathrm{~km}$ observed with the MU radar $\left(35^{\circ} \mathrm{N}\right)$, J. Atmos. Terr. Phys., 58(6), 655-660, 1996.

Rees, D., U. von Zahn, G. von Cossart, G. Nelke, K. H. Fricke, and N. D. Lloyd, The Doppler Wind and Temperature System of the ALOMAR Lidar, in Proc. 13th ESA Symposium on European Rocket and Balloon Programmes \& Related Research (Öland/Sweden), ESA SP-397, pp. 121128, 1997.

Schmidlin, F. J., The inflatable sphere: A technique for the accurate measurement of the middle atmosphere temperatures, J. Geophys. Res., 96, 22673-22682, 1991.

Taylor, M. J. and K. Henriksen, Gravity wave studies at polar latitudes, in Electromagnetic Coupling in the Polar Clefts and Caps, edited by P. E. Sandholt and A. Egeland, pp. 421-434, Kluwer Academic Publ., Dordrecht, the Netherlands, 1989.

Thrane, E. V. and U. von Zahn, ALOMAR-A new facility for middle atmosphere research at Arctic latitudes, J. Geomag. Geoelectr., 47, 921928, 1995.

Thrane, E. V., T. A. Blix, U.-P. Hoppe, F.-J. Lübken, W. Hillert, G. Lehmacher, and D. C. Fritts, A study of small-scale waves and turbulence in the mesosphere using simultaneous in-situ observations of neutral gas and plasma fluctuations, J. Atmos. Terr. Phys., 56(13/14), 1797-1808, 1994.

Torkar, K. M. and M. Friedrich, Empirical electron combination coefficients in the D and E-region, J. Atmos. Terr. Phys., 50(8), 749-761, 1988.

Torkar, K. M., M. Friedrich, and W. Riedler, Collection of D- and E-region plasma densities processed at the Technical University Graz, Report INW 8211, Tech Univ Graz, 1981.

Vincent, R. A., S. Kovalam, D. C. Fritts, and J. R. Isler, Long-term MF radar observations of solar tides in the low-latitude mesosphere: Interannual variability and comparisons with the GSWM, J. Geophys. Res., 103(D8), 8667-8683, 1998.

von Zahn, U., Achievements of ALOMAR, in Proc. 13th ESA Symposium on European Rocket and Balloon Programmes \& Related Research (Öland/Sweden), ESA SP-397, pp. 141-159, 1997.

U.-P. Hoppe (e-mail: Ulf-Peter.Hoppe@ffi.no), T. Eriksen, E. V. Thrane, T. A. Blix, J. Fiedler, and F.-J. Lübken 